\title{
A Suggested Unit in Science Based on Technology Learning Centers to Develop some Visual Thinking Skills for hearing-impaired students in middle school.
}

\section{Prof. Maher Ismail Sabry}

Professor \& EX-Head of the Department of Curriculum and Instrucion, Faculty of Education, Benha University

\section{Dr. Reda Abdel Qader Darwish}

Associate Professor of Science Education, Faculty of Education, Benha University

\section{Amira Muhammad Zaki Fathallah}

Assistant Lecturer Department of Curriculum and Instrucion, Chemistry Teaching Methods

\section{Abstract:}

7 he aim of the current research is to prepare a unit in science based on technology learning centers and to investigate its effectiveness in developing certain visual thinking skills among 8 hearingimpaired students who will be heading in the intermediate school. The researcher used the one-group quasiexperimental design in which both groups were pretested and posttested. The proposed unit " Alam al-Hayawan (Animal World)" was taught using technology learning centers. There was a statistically significant difference at the 0.01 level between the mean scores of hearing-impaired students in the first year intermediate in favor of the postadministration.

Key words: Unit in science- technology learning centersvisual thinking skills-deaf or hearing-impaired students

\section{Introduction:}

Deaf or hard of hearing is one of the disabilities that has a major impact on the personality and interactions of the disabled. It affects his language, emotional and social development, causing him to face many problems as a result of the negative impact of this disability on his interaction and communication with others and on the 
skills he possesses that qualify him to continue studying, working, and practicing various activities. (Al-Khatib, 1998, 85)

Visual thinking is one of the skills necessary for the hearing impaired in the $21^{\text {st }}$ century. The development of those skills is an important goal that the teaching of science must strive to achieve, where the visual sense represents the window through which the handicapped acquires many experiences.

Learning centers are one of the important directions of science education programs that contribute to teaching science to hard-of-hearing students, as these centers include many educational activities and media that provide an opportunity for students to go ahead with the educational mission according to their own pace, and contribute to the development these skills necessary for them (Muhammad, 2002: 1).

The integration of technology in the teaching of science also contributes to developing many skills, facilitating the learning process, and facing various challenges faced by the hearing-impaired in the learning process.

In light of this, technology was used with its various applications in learning centers to become technology learning centers, which can provide a technologyrich learning environment through many technological programs and applications that allow them to learn and gain many skills in an atmosphere full of fun and excitement.

\section{context of the problem}

Many previous studies and research such as the study of Abdul Malik (2010), the study of Abdo (2012), the study of Obaid (2016), the study of Ibrahim (2018), and the study of El-Sayed. (2018) have indicated the importance of visual 
thinking skills among the hearing impaired. Despite its importance, deficiencies in the current curriculum that are provided for the hearing impaired are very common. These curricular materials do not suit the students' needs and characteristics, as they are the same as those offered to ordinary people with some modifications represented in deleting some subjects presented to the hearing impaired who are two years older than the ordinary. They are also characterized by a lack of activities and illustrations, and the inadequacy of the means used for the nature of their impairment, which hinders skill acquisition.

Given the diversity of activities offered by the technology learning centers in the educational process that take into account the individual differences between the hearing impaired, and the freedom to choose a method of learning that suits their capabilities and preferences, and the enjoyment of learning, the current study aimed to prepare a proposed unit in science based on technology learning centers to develop some visual thinking skills that represent one of the 21st-century skills necessary for the hearing impaired.

\section{Statement of the problem:}

Given the inadequacies of the current curricula to provide intermediate students with visual thinking skills and the benefits of technology learning centers in this respect, the current research attempted to prepare a unit to develop such students' visual thinking skills

To address this problem, the current research sought to answer the following main question:

What is the effectiveness of a proposed unit in science based on technology learning centers in developing some visual thinking skills among students with hearing impairment in middle school? 
The main question was subdivided into the following subquestions:

- What is the proposed unit based on technology learning centers suitable for the hearing impaired in the middle school?

- What is the effectiveness of the proposed unit based on technology learning centers in developing the visual thinking skills of hearing-impaired students in middle school?

\section{Research aim:}

The aim of the research was to prepare a unit in science based on technology learning centers and to identify its effectiveness in developing visual thinking skills for students with hearing impairment in their first year of middle school.

\section{Research Importance:}

The importance of the current research was as follows:

- The research presents a proposed unit in science based on technology learning centers. That unit may benefit researchers and planners in developing science curricula for the hearing impaired in the preparatory stage.

- The research provides a visual thinking test of first graders who are deaf or hard of hearing. This test may be useful for researchers and teachers in measuring the level of hearing-impaired students in middle school in these skills or use it in preparing such tests.

\section{Research delimitations:}

The delimitations of the study were:

- A group of technical middle school first graders at El Amal School for Deaf in Benha.

- The following technology learning centers: Animation Center - Educational Film Center - Educational Puzzles 
and Games Center - Knowledge Web Tours Center Presentation Center.

- The following visual thinking skills: Picture description (writing)-

Analysis of the visual form and understanding each of its parts-

Optical distinction and identifying the distinct boundaries of the visual form- Infer information through pictures and figures - Use pictures and drawings to communicate ideas- Interpretation of information through symbols and signs included in the visual form.

\section{Research Terms}

Having considered definitions for the research terms, these terms can be defined as follows:

\section{Hearing-impaired students}

They are people who are lacking or deficient in the sense of hearing, which reduces their ability to hear different sounds to varying degrees. Therefore, they need special educational programs that differ from those offered to ordinary people, so that the materials consider their characteristics and needs and help them to acquire the skills necessary for them to learn and live.

\section{Visual thinking:}

It is a pattern of thinking in which the hard-ofhearing children acoustically analyze and describe the visual shape and understand the relationships between its parts, develop their visual discrimination skills, identify the distinct boundaries of the visual form, infer information through images and forms, use images to express ideas, and interpret information through symbols and signs included in the visual form.

\section{Technology learning centers}

They are corners of educational technology that are based on the use of systems, methods, tools, and technological 
means, which allow learners to practice many different activities through the availability of tools and materials to carry out these activities using multiple technology applications. Learners can move virtually from one center to another. These centers are characterized by freedom and flexibility in choosing centers and subjects in proportion to the characteristics and capabilities of learners and their needs.

\section{Literature Review:}

First: Hearing Impairment (Definition - Classification):

\section{Definition:}

Indeed, definitions of hearing impairment are varied. Among these definitions, Ibrahim (2008, 537), and Ibrahim and Sharif $(2010,119)$ defined hearing loss as: "The presence of problems that prevent the individual's auditory system from fully performing its functions or reduce the individual's ability to hear different sounds. The degree of hearing impairment can range from mild to very severe, which implies deafness. The term hearing loss refers to people who have hearing impairment or who are deaf.

Hearing loss refers also to the total or partial inability to hear sounds, which makes it impossible for the disabled to interact and communicate orally with his ordinary peers and his environment, which requires special services to take care of him and help him to communicate with his environment in ways that suit his circumstances. (Moses, 2009: 12)

In other words, hearing loss means the presence of Inner ear dysfunction that limits the individual's ability to hear different sounds, which makes him in need of special education services and programs that differ from those provided to ordinary people. 
Characteristics and Needs of the Hearing Impaired: (Ibrahim, 2003, 455; Popa \& Vanghelie, 2015, 338; Theunissen et al, 2011); Abu al-Nur and Muhammad, 2019: 219)

Research indicated that the hearing impaired have a set of characteristics, the most important of which are the tendency to individual interaction and performing their cognitive functions within the normal IQ. There IS NOT a significant correlation between the degree of hearing impairment, IQ, and delayed verbal development.

Considering these characteristics, the hearing impaired need to learn language through communication and the use of special curricular designs that are appropriate to the nature of their disabilities. They also need a supportive learning environment, and better use of teaching strategies to suit their needs and characteristics (Al-Quraiti, 2014, 70; Namukoa, 2014, 12)

Science Curriculum for Hearing Impaired Preparatory Stage:

Despite the importance of the science subject for the hearing impaired and its role in providing them with many necessary experiences and skills, the current science curricula offered for the hearing impaired preparatory stage do not meet their needs and do not reflect their special interests. Ahmed (2005)

Several studies have focused on developing, preparing curricula and programs in science for the hearing impaired to achieve effective learning for this category of disabled persons. These studies include Ahmed in 2005, Muhammad in 2007, Obaid in 2010, Muhammad in 2011, Naseer in 2013, and Mohamed in 2016.

Effective science teaching approaches and strategies for the hearing impaired include the environmental approach, 
learning through drama, the problem-solving method, individualized learning method, survey-based learning.

Also they include the use of visual tools and schemes such as the use of concept maps that show the visual relationships between scientific concepts, the use of multimedia, gameplay, visual aids, active learning, and school activities like silent acting and artistic activities, learning centers, and cooperative learning. (Muhammad, 2002 Lang \& Steely ,; Easterbrook \& Scheetz; 2004, 261; Al-Huthaili, 2005; Al-Qatawi, 2012; Mazen, 2012, 117; Patalano, 2015, 33; Namukoa , 2014, 42; Saad, Dandashi, Aljaam \& Saleh, 2016; Taha, 2017, 105; Abdullah, 2017)

Second: visual thinking: (definition - importance skills, and methods of its development)

Visual thinking is defined as one of the patterns of thinking that arises as a result of provoking the mind with visual stimuli. This entails understanding the relationships between concepts, which helps it in solving problems. (Ibrahim, 2006, 82), Al-Shilwa defines it $(2017,245)$ as the ability to understand, interpret, distinguish, and create images and visual forms, and to create relationships between them.

\section{The importance of visual thinking}

The importance of visual thinking is to increase students 'ability to absorb visual messages, develop their creativity and innovation capabilities, understand abstracts, link ideas together in an easily understandable manner, understand the world and the surrounding environment, and develop the ability to solve problems. (Ammar and al-Qabbani, 2011, 31-31, 2011; Abdo, 2012, 38; Plow, 2004)

From the above, the importance of visual thinking for students with hearing impairment is evident. They rely primarily on the sense of sight and build experiences of 
what is happening around them, including situations and events. Therefore, the development of visual thinking and its skills among the hearing impaired contributes to increasing their motivation to learn, to establish information in their memories, and to understand abstract concepts.

\section{Visual thinking skills and methods for developing:}

The visual thinking skills are as follows: (Amer and AlMasry, 2016, 89-90)

1. Recognizing and describing shapes: the individual's ability to recognize the dimensions and nature of all the visible characteristics of the visual stimulus.

2. Optical Discrimination: It refers to the ability to recognize and distinguish objects presented visually.

3. Interpreting visual information: the individual's ability to clarify the implications of the visual stimulus, including graphics and signs.

4. Awareness of spatial relationships: It indicates the ability to link the visual stimulus to the surrounding reality of this stimulus and know the relationship between them.

5. Shape analysis: It refers to the ability to see the relationships within the visual stimulus, and to define and classify those relationships.

6. Awareness of visual deception: identifying the shortcomings and defects in the visual stimulus, and guiding thinking in the right direction.

7. Creation and training: the ability to transform ideas and information in their various forms and represent them in the form of meaningful forms and drawings.

8. Extracting meanings: the ability to extract new meanings and reach scientific concepts and principles through the visual stimulus. 
To develop these skills, Matar $(1018,176-177)$ indicates that there are some strategies that contribute to developing visual thinking and skills. These strategies include a puzzle strategy and a computer-generated mind maps strategy.

Many previous studies concerned with developing visual thinking skills among hearing-impaired students indicated the effectiveness of some teaching remedies electronically in developing their visual thinking skills such as the use of thinking maps and the effectiveness of augmented reality (Abdo, 2012; Ibrahim, 2018 El Sayed, 2018)

\section{Third: Technology learning centers and their characteristics:}

Technology learning centers represent a group of corners or virtual areas that are based on the use of technology methods, tools and programs in planning, implementing, and evaluating the teaching and learning process. Examples include WebQuest, the Presentation Center, the Animation Center, and the Story Center (Electronic / Digital), And an electronic educational games center.

Technology learning centers are stable ones, where learners can move virtually from one center to another. Thus, it is possible to provide many centers within the same place and at the lowest costs. It is based on the use of technological means and tools, and learners are provided with all means of support electronically.

\section{Research hypothesis}

The research tried to verify the following hypothesis:

- There is a statistically significant difference at the 0.01 level between the mean scores of the study group in the pre-post administrations in the visual thinking skills test in favor of the post measurement. 


\section{Research Procedures:}

First: Reviewing the literature and previous studies related to research variables and fields.

Second: Preparing the proposed unit, which includes the following:

- Choosing the topic of unity, which is " Alam al-Hayawan (Animal World)"

- Identifying the unit goals, its scientific content, and technology centers, as well as the evaluation methods used.

- Designing the unit electronically by designing the technology centers used in each topic of this unit with its goals, content, and activities and evaluating, with the help of an educational technology specialist. This unit included the following topics: (Diversity in living organisms - Producers and Consumers - AdaptationDiversity of animal environments).

- Preparing a student counselor explaining to him the subjects he studies in the unit, supported by pictures and centers used for each topic, and a schedule for following up work inside the centers.

- Preparing the teacher's guide to assist the teacher in the teaching of the proposed unit in accordance with technology learning centers.

- Presenting the unit (with its tools) in its initial form to a group of specialists in the field of Curriculum and Pedagogy in Science, and science teachers in schools for the deaf, as well as specialists in the field of educational technology, to judge its validity, and make adjustments according to the observations of the arbitrators. By that, the answer to the first sub-question was reached On What is the proposed unit based on 
technology learning centers suitable for the hearing impaired in the preparatory stage?"

Third: Investigating the effectiveness of the proposed unit based on technology learning centers in developing visual thinking skills for technical middle school first graders, through the following procedures:

1. Preparing the research tool represented in the visual thinking test, according to the following steps:

- Determining the objective of the test: It is to measure some of the visual thinking skills of hearing impaired pupils in the first preparatory grade, which is represented in the following skills: Picture description (writing)Analysis of the visual form and understanding each of its parts- Optical distinction and identifying the distinct boundaries of the visual form- Infer information through pictures and figures - Use pictures and drawings to communicate ideas- Interpretation of information through symbols and signs included in the visual form.

- Reviewing the literature and previous studies concerned with visual thinking and measuring it, to determine the procedural definition of each of visual thinking and its skills.

- Preparing the EFL vocabulary test: Test vocabulary reached (30) multiple-choice types; Five vocabularies were identified to measure each sub-skill of visual thinking skills.

- Determining the test instructions.

- Estimating test scores where one score was specified for each item in the case of the correct answer, and zero in the case of the wrong answer, and the test is corrected electronically.

- The exploratory testing: The test was administered to 60 fourth-grade primary school students at the School facility Greater Elementary No. 1, to calculate the 
psychometric properties of the test (due to the small size of the exploratory group), and the test was also applied to a group consisting of 10 middle school first graders who are deaf or hard of hearing (other than the study group) to calculate the test time.

A. Establishing test validity

The integrity of the visual thinking test was confirmed by:

- Virtual Honesty: that is by presenting it to a group of arbitrators in the field of science education in order to judge its validity. the amendments were made in the light of the opinions and directions of the arbitrators.

\section{- Item validity:}

Correlation coefficients were estimated between the score of each item and the degree of the dimension to which it belonged after removing the item degree from the dimension degree. The correlation coefficients between each dimension score and the overall score of the test were also estimated after the dimension score was removed from the total score. Correlation coefficients ranged between $(0.4$ - 0.657). Correlation coefficients values ranged between the score for each dimension and the overall score for the test after deleting the dimension score between (0.665-5.737). All of them are statistically significant at (0.01) level, which indicates the validity of the test.

\section{B. Establishing test reliability this is done by:}

- Re-application of the test: The visual thinking skills test was applied to 60 fourth-grade primary school students, and the application was re-applied to them at a time interval of two weeks. The correlation coefficient between the two students 'mean scores in the two applications was (0.788), which indicates the stability of the test.

- Estimating coefficient of stability using the Alpha Cronbach coefficient for dimensions or skills and for 
testing. The values of the alpha coefficients ranged from 0.551 to 0.724 , indicating the stability of the test.

- Internal consistency of $a$ test:

The correlation coefficients were estimated between the score of each item and the degree of dimension to which the item belongs. Correlation coefficients were also estimated for each dimension score and the overall score for the test. The values of correlation coefficients ranged between the degree of each item and the degree of the dimension to which they belonged between 0,394-0,809. The values of correlation coefficients ranged between the score for each dimension and the overall score for the test between 0,368-0,707. All these values are statistically significant at the 0.01 level, which indicates the stability of the internal consistency of the test.

C. Calculation of test time: The test was applied to 10 middle school first graders at Al Amal School for the Deaf in Benha (other than the study group) to calculate the test time by calculating the average time taken by the study group to answer the test questions, using the following formula:

- With the addition of five minutes to clarify the test instructions for students, thus, the appropriate time for the test will be (40) minutes.

- The final form of the test: After testing and verifying its sincerity and reliability, the test became final and valid for use. The following table shows the number of items for each sub-skill of visual thinking skills.

- The implementation of the study experiment. It went through the following stages:

- Choosing the study group which was represented in the middle school first graders at Al-Amal School for the Deaf in order to measure the effectiveness of the proposed unit. 
Table (1) Visual thinking sub skills and their items

\begin{tabular}{|c|c|c|c|}
\hline No & Visual thinking skills & $\begin{array}{c}\text { No of } \\
\text { Items }\end{array}$ & Item Numbers \\
\hline 1 & Picture description (writing) & 5 & $\mathbf{7 , 1 1 , 1 5 , 2 1 , 2 3}$ \\
\hline 2 & $\begin{array}{c}\text { Analvsis of the visual form and } \\
\text { understanding each of its parts }\end{array}$ & 5 & $\mathbf{5 , 8 , 1 9 , 2 4 , 2 8}$ \\
\hline 3 & $\begin{array}{c}\text { Optical distinction and identifying the } \\
\text { distinct boundaries of the visual form }\end{array}$ & 5 & $1,4,6,9,14$ \\
\hline 4 & $\begin{array}{c}\text { Infer information through pictures and } \\
\text { figures }\end{array}$ & 5 & $\mathbf{2 , 3 , 1 6 , 2 5 , 3 0}$ \\
\hline 5 & $\begin{array}{c}\text { Use pictures and drawings to communicate } \\
\text { ideas }\end{array}$ & 5 & $10,18,20,22,27$ \\
\hline 6 & $\begin{array}{c}\text { Interpretation of information through } \\
\text { symbols and signs included in the visual } \\
\text { form. }\end{array}$ & 5 & $12,13,17,26,29$ \\
\hline \multicolumn{3}{|c|}{ Total item test 30 } \\
\hline
\end{tabular}

- Applying the research tool represented in pre-testing the visual thinking skills to the study group, before teaching the proposed unit to obtain the necessary Pre-grading for the statistical treatment of the research results.

- Teaching the proposed unit based on technology learning centers for the study group pupils. Teaching the subjects of the unit required eight classes. Three electronic centers were provided to study each of these topics, considering the number of students in each center so that the center does not exceed four students.

- Applying the post-test of the visual thinking to the study group, after completing the teaching of the proposed unit.

\section{Research Results:}

\section{Fourth: data monitoring and statistically processing}

The research hypothesis states that "there is a statistically significant difference at the 0.01 level between the mean scores of the research group in the pre and post measurements in the visual thinking skills test in favor of the post measurement". The results were as follows:

First: Calculating the arithmetic mean and the standard deviation in the pre and post measurements of the visual 
thinking skills included in the visual thinking test as well as the total score, as shown on Table 2.

Table (2) Arithmetic mean and standard deviation in the pre and post administration of visual thinking skills included in the visual thinking test as well as the overall score

\begin{tabular}{|c|c|c|c|c|c|}
\hline Skill & $\begin{array}{l}\text { App. } \\
\text { type }\end{array}$ & $\begin{array}{c}\text { MIN } \\
\text { degree }\end{array}$ & $\begin{array}{l}\text { Max. } \\
\text { degree }\end{array}$ & avg. & Std. Dev \\
\hline \multirow[t]{2}{*}{ Picture description (writing) } & Before & 2 & 3 & 2,375 & 0.52 \\
\hline & After & 3 & 5 & 3.75 & 7,07 \\
\hline \multirow{2}{*}{$\begin{array}{l}\text { Analvsis of the visual form } \\
\text { and understanding each of } \\
\text { its parts }\end{array}$} & Before & 2 & 2 & 2 & 0 \\
\hline & After & 3 & 5 & 3,625 & 0.74 \\
\hline \multirow{2}{*}{$\begin{array}{l}\text { Ontical distinction and } \\
\text { identifving the distinct } \\
\text { boundaries of the visual } \\
\text { form }\end{array}$} & Before & 1 & 3 & 2 & 0.756 \\
\hline & After & 3 & 5 & 3,875 & $\mathbf{0 , 8 3}$ \\
\hline \multirow{2}{*}{$\begin{array}{l}\text { Infer information through } \\
\text { pictures and figures }\end{array}$} & Before & 1 & 3 & $\mathbf{1 , 8 7 5}$ & 0.83452 \\
\hline & After & 2 & 5 & 3,375 & 0.91613 \\
\hline \multirow{2}{*}{$\begin{array}{l}\text { Use nictures and drawings to } \\
\text { communicate ideas }\end{array}$} & Before & 2 & 3 & 2,125 & $\begin{array}{l}\mathbf{0 . 3 5 3 5 5} \\
\end{array}$ \\
\hline & After & 2 & 4 & 3,25 & 0.770 \\
\hline \multirow{2}{*}{$\begin{array}{l}\text { Internretation } \\
\text { information through svmbols } \\
\text { and signs included in the } \\
\text { visual form }\end{array}$} & Before & 1 & 3 & 2 & $\begin{array}{l}0.53452 \\
\end{array}$ \\
\hline & After & 2 & 5 & 3,375 & 0.916 \\
\hline \multirow{2}{*}{$\begin{array}{llll}\begin{array}{l}\text { Overall score } \\
\text { thinking skills }\end{array} & \text { for visual } \\
\end{array}$} & Before & 10 & 15 & 12,375 & 1.50594 \\
\hline & After & 19 & 25 & 21,25 & 1,83225 \\
\hline
\end{tabular}

Second: Using the Wilcoxon test for the associated samples to calculate the significance of the differences between the mean of the research group levels in the pre and post measurements, as shown in Table 3.

It is clear from the previous table that $\mathrm{z}$ values for significant differences between the pre and post measurements of visual thinking skills are significant at the 0.01 level. Thus, the research hypothesis, which states that "there is a statistically significant difference at 0.01 level between the mean scores of the research group in the pre and post measurements in the visual thinking skills test (sub-skills and the total degree) in favor of postmeasurement, is validated." This is an indication of the effectiveness of technology learning centers in developing visual thinking skills for the study group. 
Table (3) value of $\mathrm{z}$ for significant differences between the pre and post measurements of visual thinking skills "and the overall score using the Lucoxen test.as the overall score

\begin{tabular}{|c|c|c|c|c|c|c|}
\hline Skill & RNK & No & $\begin{array}{l}\text { Mean } \\
\text { RNK }\end{array}$ & T RNK & Z- Val & Significance level \\
\hline \multirow{4}{*}{ Picture description (writing) } & $\begin{array}{c}\text { Pos. } \\
\text { ranks }\end{array}$ & 7 & 4 & 28 & \multirow{4}{*}{2,43} & \\
\hline & $\begin{array}{l}\text { Neg. } \\
\text { ranks }\end{array}$ & $\mathbf{0}$ & O & $\mathbf{0}$ & & \\
\hline & Equal & 1 & & & & \\
\hline & Total & 8 & & & & \\
\hline \multirow{4}{*}{$\begin{array}{l}\text { Analysis of the visual form and } \\
\text { understanding each of its parts }\end{array}$} & $\begin{array}{c}\text { Pos. } \\
\text { ranks }\end{array}$ & 8 & 4,50 & 36 & \multirow{4}{*}{2,565} & \\
\hline & $\begin{array}{l}\text { Neg. } \\
\text { ranks }\end{array}$ & 0 & 0 & $\mathbf{0}$ & & \\
\hline & Equal & $\mathbf{0}$ & & & & \\
\hline & Total & 8 & & & & \\
\hline \multirow{4}{*}{$\begin{array}{l}\text { Optical distinction and } \\
\text { identifying the distinct } \\
\text { boundaries of the visual form }\end{array}$} & $\begin{array}{c}\text { Pos. } \\
\text { ranks }\end{array}$ & 8 & 4,50 & 36 & \multirow{4}{*}{2,549} & \\
\hline & $\begin{array}{r}\text { Neg. } \\
\text { ranks }\end{array}$ & 0 & 0 & $\mathbf{0}$ & & \\
\hline & Equal & $\mathbf{0}$ & & & & \\
\hline & Total & 8 & & & & \\
\hline \multirow{4}{*}{$\begin{array}{l}\text { Infer information through } \\
\text { pictures and figures }\end{array}$} & $\begin{array}{c}\text { Pos. } \\
\text { ranks }\end{array}$ & 6 & 3,50 & 21 & \multirow{4}{*}{2,449} & \\
\hline & $\begin{array}{l}\text { Neg. } \\
\text { ranks }\end{array}$ & $\mathbf{0}$ & 0 & $\mathbf{0}$ & & \\
\hline & Equal & 2 & & & & \\
\hline & Total & 8 & & & & \\
\hline \multirow{4}{*}{$\begin{array}{l}\text { Use pictures and drawings to } \\
\text { communicate ideas }\end{array}$} & $\begin{array}{c}\text { Pos. } \\
\text { ranks }\end{array}$ & 7 & 4 & 28 & \multirow{4}{*}{2,46} & \\
\hline & $\begin{array}{l}\text { Neg. } \\
\text { ranks }\end{array}$ & 0 & 0 & 0 & & \\
\hline & Equal & $\mathbf{1}$ & & & & \\
\hline & Total & 8 & & & & \\
\hline \multirow{4}{*}{$\begin{array}{l}\text { Interpretation of information } \\
\text { through symbols and signs } \\
\text { included in the visual form }\end{array}$} & $\begin{array}{c}\text { Pos. } \\
\text { ranks }\end{array}$ & 7 & 4 & 28 & \multirow{4}{*}{2,414} & \\
\hline & $\begin{array}{l}\text { Neg. } \\
\text { ranks }\end{array}$ & 0 & $\mathbf{0}$ & $\mathbf{0}$ & & \\
\hline & Equal & 1 & & & & \\
\hline & Total & 8 & & & & \\
\hline \multirow{4}{*}{$\begin{array}{l}\text { Overall score for visual } \\
\text { thinking skills }\end{array}$} & $\begin{array}{c}\text { Pos. } \\
\text { ranks }\end{array}$ & 8 & 4,50 & 36 & \multirow{4}{*}{2,536} & \\
\hline & $\begin{array}{l}\text { Neg. } \\
\text { ranks }\end{array}$ & 0 & 0 & 0 & & \\
\hline & Equal & $\mathbf{0}$ & $\mathbf{0}$ & $\mathbf{0}$ & & \\
\hline & Total & 8 & 0 & 0 & & \\
\hline
\end{tabular}

\section{Discussing Research Findings:}

The research results show the following:

- Improvement in picture description skill was due to the activities practiced by the students inside the 
technology learning centers, where the students described many pictures related to topics emanating from the environment in which they live.

- The improvement of the skill of analysis of the visual form and understanding each of its parts is mainly due to the activities practiced by the students inside the technology learning centers used, where they analyzed many images by identifying the elements that make up the images and shapes, determining the relationship between each component and the other, and analyzing images of a group of Organisms to put them in a place that matches their characteristics. This would develop that skill.

- The improvement of the skill of optical distinction and identifying the distinct boundaries of the visual form is mainly due to the activities practiced by the students inside the learning centers used, where they examined a set of images and shapes to determine what differentiates them from the other, collect a set of images that distinguish the environments in which some animals live, and distinguish between different images to select the right image or shape through play.

- The improvement of the skill of inferring information through pictures and figures is mainly due to the activities practiced by students within the learning centers used, as those activities included their analysis of shapes and images and reaching out through them to the appropriate conclusions.

- The improvement of the skill of interpreting information through the symbols and signs included in the visual form is mainly due to the activities carried out by students within the learning centers used, where they provided logical interpretations of events and phenomena through their examination of pictures and 
drawings, and the selection of images that explain some events and phenomena.

\section{Suggestions for further research:}

Considering the findings of the current research, we recommend the following:

- Pre-service and in-service teacher-training to use various and effective educational approaches, methods, and teaching strategies to develop visual thinking skills for hearing impaired students.

- Providing educational content for the hearing-impaired pupils in all subjects, especially science, in various ways and methods that suit their preferences and directions.

- Research proposals:

- Considering the research results, the following is suggested:

- A program based on technology learning centers to develop health awareness among students with hearing impairments in basic education.

- Developing a science curriculum for the preparatory stage for the hearing impaired considering the requirements of the twenty-first century.

\section{References}

\section{Arabic references}

Ibrahim, Magdy Aziz (2008). Development of thinking for students with special needs. Cairo: The World of Books.

Ibrahim, Magdy Aziz (2003). Education curricula for people with special needs in light of their human, social and cognitive requirements. Cairo: The Anglo-Egyptian Library.

Ibrahim, Zeinab Mohamed Fathi (2018). A proposed electronic system based on thinking maps to develop some skills of visual thinking and reading comprehension for hearing impaired students. Unpublished Doctorate, Faculty of Graduate Studies in Education, Cairo University. 
Ibrahim, Abdullah Ali (2006). The effectiveness of using visual thinking networks in science to develop Gane's cognitive levels and visual thinking skills for middle school students, the tenth scientific conference, scientific education, challenges of the present and future visions, first volume, the Egyptian Society for Scientific Education, Faculty of Education, Ain Shams University, 30 July - 1 August .

Abu Al-Nour, Mohamed Abdel Tawab Moawad, and Mohamed, Amal Jumaa Abdel Fattah (2019). Teaching and learning strategies for people with special needs. Cairo: Dar Al Zahra.

Ahmed, Muhammad Rushdi Abu Shama (2005). A proposed approach in science for the hearing impaired in the light of the meaningful learning theory and its effectiveness in achieving some of the goals of teaching science. Unpublished $\mathrm{PhD}$, Faculty of Education, Mansoura University.

Khatib, Jamal (1998). Introduction to hearing impairment. Jordan: Dar Al-Fikr Al-Arabi.

El-Sayed, Mohamed Rashdan Ali (2018). Designing an e-learning environment based on augmented reality technology for hearing impaired students and its impact on developing concepts and some visual thinking skills. Unpublished Doctorate, Faculty of Education, Fayoum University.

Al-Shalawi, Abdel-Ali Mohamed Abdel-Ali (2017). The availability of visual thinking skills in science curriculum for the sixth grade of primary school. International Specialist Educational Journal, Volume 6, (3), 243-251.

Taha, Najat Fathi Saeed (2017). Hearing impairment and mind habits. Cairo: The Anglo-Egyptian Library.

Amer, Tariq Abdul Raouf, Al-Masry, Ihab Eisa (2016). Visual thinking: its concept- its skills - its strategies. I 1, Cairo: The Arab Group for Training and Publishing.

Abdullah, Souad Fouad Ahmed (2017). The effectiveness of applying the play strategy in developing the creative thinking ability of hearing-impaired children in the kindergarten stage. Unpublished Master. Faculty of Education, Suez Canal University.

Abdul-Malik, Loris Emil (2010). A built-in e-learning program based on the visual and spatial approach to developing achievement in science, optometry reading skills and selfesteem among preparatory students with hearing impairment. Studies in Curricula and Teaching Methods, 159, 150-209. Abdel Moneim, Ali (2005). Visual thinking strategies and educational practice .Academic Library 
Abdo, Amani Rabei Al-Hussaini (2012). The effectiveness of using thinkingmaps to obtain science and developing some visual thinking skills for hearing impaired students in the primary stage. Unpublished MA, Faculty of Education, Mansoura University.

Obaid, Iman Al-Sayed Suleiman (2010). The effectiveness of the instrumental enrichment program in developing some thinking skills and academic achievement for students with hearing impairment in the science subject at the preparatory and vocational stage. Unpublished MA, Faculty of Education, Mansoura University.

Obaid, Iman Al-Sayed Suleiman (2016). The use of some active learning strategies in developing the processes of science and visual perception, and the effect of learning on science subject remains for the hearing-impaired students in the primary stage. Unpublished Doctorate, Faculty of Education, Mansoura University.

Attio, Mohamed Naguib Mustafa (2013). Methods of teaching science between theory and practice. Cairo: Dar Al-Fikr AlArabi.

Ammar, Muhammad Eid and al-Qabbani, Najwan Hamed (2011). Visual thinking in light of educational technology. Alexandria: New University House.

Al-Quraiti, Abd al-Muttalib Amin (2014). People with hearing impairment: their definition, characteristics and education. Cairo: The World of Books.

Al-Qatawi, Sahar Mansour (2012). The effectiveness of a school activities program in developing creative thinking among a sample of hearing-impaired children. Educational and psychological studies, Journal of the Faculty of Education, Zagazig, 76, 72-116.

Mazen, Hussam Muhammad (2012). Educational curricula for people with special needs. Cairo: Academic Library.

\section{Non-Arabic references}

Easterbrooks , S. R. \& Scheetz , N. A. (2004). Applying critical thinking skills to character education and values clarification with students who are deaf or hard of hearing. American Annals of the Deaf, 149 (3), 255-263.

Lang, H. G. \& Steely, D. (2003). Web-based science instruction for deaf

students: What research says to the teacher. Instructional Science, 31, 277-298. 
Namukoa , A. W. (2014). Teacher practices in science literacy instruction for learners who are deaf or hard of hearing in Kenya. published master thesis, University of Alberta.

Patalano, F. l. (2015) . Science based education for students who are deaf and/ or Hard of hearing. published doctoral dissertation , Arcadia University.

Plough,J. M. (2004): Students Using Visual Thinking to Learn Science in a Web-based environment, Unpublished doctoral dissertation , Drexel University.

Popa, M. \& Vanghelie, M. L. (2015). Elements of experiential psychotherapy in the development of the social and emotional skills of the hearing-impaired students. Procedia Social and Behavioral Sciences,187, 338- 342.

Saad,S., Dandashi, A., Aljaam, J. M. \& Saleh,M. (2016). The multimedia-based learning system improved cognitive skills and motivation of disabled children with avery high rate.Journal of Education Technology \& Society, 18(2) , 366379.

Theunissen ,S.C. , Rieffe,C. , Kouwenberg,M., Soede,W., Briaire,J. and Frijins,J.H.M. (2011). Depression in hearing - impaired children . International Journal of Pediatric Otorhinolaryngology , 75, 1313-1317.

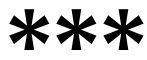

